$\xi=-1$

\title{
Peer-reviewed active learning engagement with a multi-level remedial class
}

\author{
Nor Alwani Omar*, Ezzah Suraya Sarudin, Arfah Mohd Nasir, Suraya Masrom, Norhasliza Ahmad \\ Faculty of Computer and Mathematical Sciences, Universiti Teknologi MARA (UiTM), Perak Branch, Tapah Campus, \\ Tapah Road, 35400 Perak, Malaysia \\ Corresponding author E-mail: noralwani@perak.uitm.edu.my
}

\begin{abstract}
This study was conducted to find the effectiveness of the remedial class to the students' performance in Mathematical courses. Two objectives were highlight which are the active learning engagement among participants and the effectiveness of the remedial class. The respondents of this study is 169 semester one students of Diploma in Sciences. All students were involved in the first remedial class and the result of the students later was compared with the previous semester. The result shows there is improvement in students' performance as the failure rate for that semester is lower compared to the previous one. Next, students who passed in Pre-calculus was divided into two groups for the next semester. The control group proceed with calculus I without second remedial class while the experimental group need to attend second remedial class. The result of these students in Calculus I later was collected and analyzed. The statistics shows there is slight improvement in failure rate for experimental group. Thus, it shows that multi-level remedial class is a new effective approach to improve students' poor foundation in Mathematics. Besides, it is indirectly beneficial to the faculty and university as there will be less students who do not graduate on time.
\end{abstract}

Keywords: Active learning; peer-reviewed; remedial class; Mathematical courses; Calculus.

\section{Introduction}

Mathematics is an important subject to all students, no matter what field they are studied. Many people have argued about the importance of this subject to different fields such as accounting, applied science and engineering. Some said that Mathematics is not supposed to be a part of their programme's syllabus as the existence has negatively affect the students' result. Besides, there are some of them said that Mathematics does not give any benefit to the students and should only be taught during school. However, some researcher has denied the argument and found that Mathematics is very important to everyone whether they are not students or not. According to [1], learning and studied Mathematics is significant action since it is highly related to both academic and career opportunities. Besides, they believe that the Mathematical skills are very helpful for future career enhancement. In Universiti Teknologi MARA (UiTM) Perak Branch, Tapah Campus, we find that students of Diploma in Sciences were having problem in Mathematical courses such as Pre-Calculus and Calculus 1. Most students think that these courses are burdensome and affecting their Integrated Cumulative Grade Point Average (iCGPA) negatively. Besides, they keep questioning about the relevance of these courses in their program's study plan. The students did not realize that Mathematical courses are important to science and its properties are needed as basic requirement for all science, as mentioned by [2] in their study. Over time, their attitude over these courses are worsen and consider the subjects are just necessities to graduate.

As a well-known university, UiTM is very concern about two things which are high-failure rate and the Graduates on Time (GOT). Because of that reasons, the hot topic discussed by the top management is about the high failure rate in Mathematical courses Two out of three Mathematical courses offered to science students are always on the list of subjects that achieved failure rate more than $25 \%$. Not only UiTM, educators in other higher learning institutions also had seriously debated about the high-failure rate in Mathematical courses. For instance, some private universities are having high failure rate in both Business Mathematics and Business Statistics that was taught for management students. Besides, some of the students could not graduate on time because of these two subjects. This issue has become a huge concern as it is getting more serious over time. As for UiTM, the Pre-Calculus and Calculus 1 subjects that was offered to science students in UiTM have been in the list of high failure rate for a few semesters consecutively. Some put the fault on the lecturers and some said that the students are very weak. However, pointing finger on each other is not a solution, so it will not solve the problem. In addition, these two subjects are pre-requisite subjects and the failure in any of this course might lead to a bigger problem. Generally, when students failed any pre-requisite courses, the chances of extension of study period is very high. Thus, it definitely will affect the statistics of GOT for students of Diploma in Sciences and give a huge blow to the faculty itself.

From the past research, [3] find that the main problem among science students is the poor foundation in basic Calculus and have recommended a remedial class as an approach to improve the students' performance. This approach was supported by [4] that mention remedial class as one of the reliable approaches in learning process since they find that students face difficulties to carry the fundamental knowledge. However, the question is whether this approach is effective or not. Thus, this study has been conducted to find the effectiveness of the suggested approach. Following are the research objectives and research questions of this research: 


\subsection{Research Objectives}

1. To conduct a multi-level remedial class that supports peerreviewed active learning engagement.

2. To find the effectiveness of the multi-level remedial class in reducing failure rates in Mathematics courses among science students.

\subsection{Research Questions}

1. What are the content of the learning module use for the multi-level remedial class?

2. What are the statistics of students answering all the questions during the multi-level remedial class?

3. What is the percentage of failure rate for Pre-calculus after the first remedial class conducted?

4. What is the percentage of failure rate for Calculus I for students who attend two remedial class?

5. What is the percentage of failure rate for Calculus I for students who attend only one remedial class?

\subsection{Significance of This Study}

1. The management could use this important information in planning the various academic programs in UiTM.

2. The finding could give important inputs to Mathematics lecturers in improving their approach for weak students. Meanwhile, it will help students to have early preparation for upcoming semester.

3. The researchers could use the finding as a guideline for future improvement in their research.

\section{Literature Review}

Mathematical courses such as Pre-Calculus, Calculus I and Calculus II are the common subjects that received extra attention in higher learning institutions. These subjects are offered in most of the programs taught at university level and caused a huge problem as it still not improving after implementation of all sort of strategies. The strategies included extra class, Mathematics clinic, extra exercises, Mathematics' consultation hour and etc. Even after the implementation of all these approaches, the high failure rate in Mathematics still remained. Therefore, UiTM has put an extra attention on these subjects to ensure that the students will passed this subject and graduate on time. An extra action is necessary since there are some students that extended their study for another one year only because they still do not pass the Mathematical courses. A research by [5] has reported that the failure rate of diploma students at UiTM Sarawak is more than $30 \%$ and it is not only happened in the faculty of Mathematics. According to [6], the high failure rate of Mathematical courses also happens among engineering students. This problem has become crucial as it is not only among science students but also involved the students from different backgrounds. Besides that, a study by [7] conducted in Universiti Teknologi Malaysia (UTM) also has reported that they are facing difficulties in teaching and learning of Calculus.

The high failure rate in Mathematical courses are generally connected to the basic foundation of Mathematics. Students generally learn the basic of Mathematics during school. So, the weakness of approach used during school has fully impact university students' understanding. Instead of that, we find that some methods taught by schools' teachers focused on the answer only instead of the correct techniques to get the answer. Because of that, university students find that it hard to carry the fundamental knowledge as they learn more about the subject. In addition, they are getting more confused and lost their direction on this subject. In [8] mentioned that students who perform poorly in the basis Calculus examination at university had perform poorly in their SPM Addi- tional Mathematics too. For that reason, in [3] has suggested three methods to handle this issue. Firstly, students need to change their mindset on this course and cooperate well during the learning process. Next, students need to consult their lecturers whenever they have any problem related to Mathematics. Lastly, the suggested to set up a remedial class for new students as a way to improve their foundation in Mathematics. Among the three suggested methods, remedial class is an ideal approach since the other two methods are hard to control. Besides, mindset needs mental motivation and continuous support from surrounding people, not only lecturers. Besides, the second approach was continually implemented by all lecturers in all institutions.

Remedial class was introduced to improve the performance of students who are not ready for the university-level syllabus. According to [9], instructor of Mathematics remedial class has highlight three challenges during their lesson. The first one lacks conceptual understanding of Mathematical principles, the consequences of the early use of calculator, and the lack of confidence in students due to private tutoring services. Therefore, conducting a remedial class is an effort in education to overcome the weak students in particular courses [10]. Instead of that, in [11] also stated that about $76 \%$ of 25 universities in Spain has conducted foundation or remedial class as a way to reduce new students' failure. This activity is a collaborative work between university and secondary school to prepare students for university-level lesson. Therefore, this research aims to determine the effectiveness of the remedial class on Diploma in Sciences students in UiTM Perak Branch, Tapah Campus.

\section{Methodology}

This study conducted to provide a well-designed module as an approach to improve basic foundation of Mathematics among science students. The aims of this research are to conduct an effective remedial class and reduce the failure rate in Mathematical courses. Therefore, a multi-level remedial class was designed for science students in UiTM Perak Branch, Tapah Campus to find the effectiveness of this approach.

\subsection{Population}

The respondents of this study are the semester 1 students of Diploma in Sciences for semester December 2016 to March 2017. There are 169 students from different background and skills.

\subsection{Data Collection Procedure}

The research begins with the development of two set of modules for the multi-level remedial classes. The content of both of the modules was designed based on the result from [3]. A study has previously conducted to ensure the suitability of the content with respondents. The first module was designed for the first remedial class which is involved science students that will sit for subject Pre-Calculus (MAT133) in current semester. The students' answer for the first module was collected to answer the first research objective which is about the active learning engagement. At the end of the semester, the respondents' result was collected and analyzed. Next, the second remedial class was conducted in the next semester using the second module that was designed relevant to the subject taken for that semester which is Calculus I (MAT183). In this stage, the respondents were divided into two groups. One group became the control group and do not attend the second remedial class. While, the second group became the experimental group and attend both of the remedial class. At the end of the semester, the result of these two groups of respondents will be compare and analyze to determine the effectiveness of the module and remedial class. Fig. 1 shows the flow of the research. 


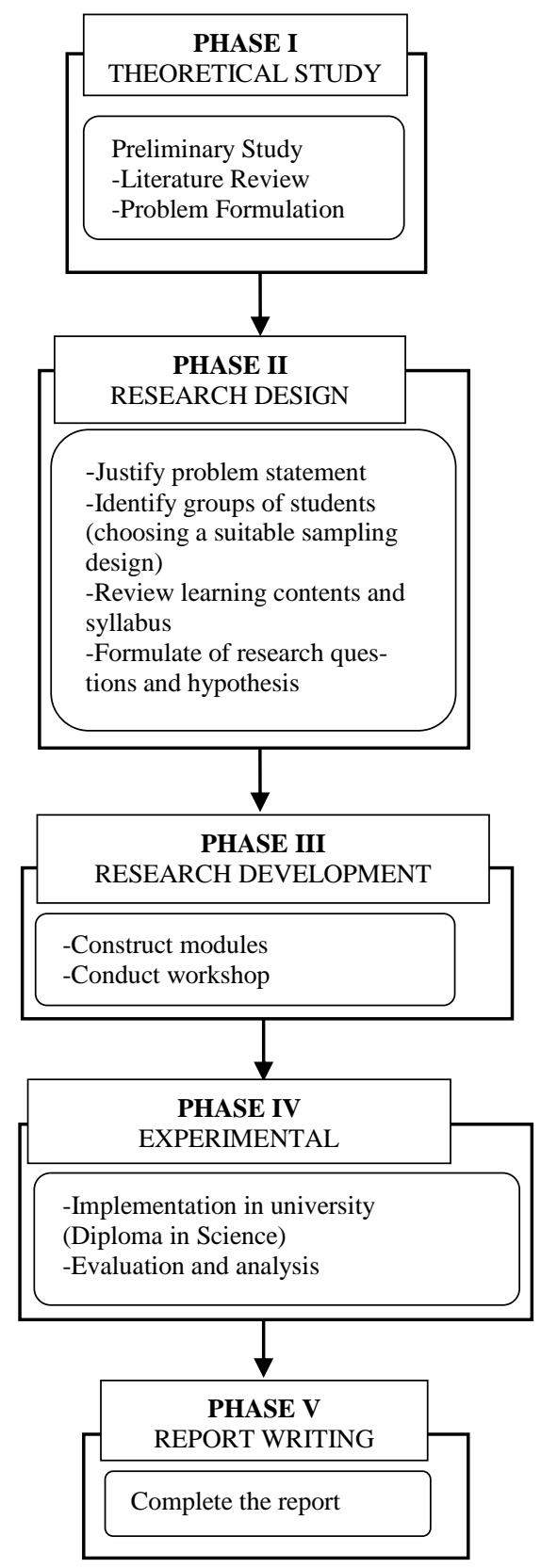

Fig. 1: Research flowchart

\subsection{Data Analysis Procedure}

The analysis of the result of the students was generated from Microsoft Excel. The students' learning engagement was measured by checking the number of questions answered. Through the submission, we able to determine whether the remedial class was welcome by students or not. Meanwhile, the effectiveness of the remedial class was measured through the students' result. The result was compared with the previous result of students who never attend remedial class.

\section{Results and Discussion}

The result shows that the first remedial class has received positive feedback from students as all 169 students willing to participate and be respondents of this study.

The first remedial class was handling by an instructor whom also an experience lecturer. After a short discussion on the highlighted topics, students were given a set a question to be answered and submitted. From the submitted exercises, this study measured the active learning engagement of students. It was found that about
$36 \%$ of the respondents has answered all the questions given, $52 \%$ answered more than half and the rest answered less than half. The figures shown that most students are working hard to improve their basic foundation in Mathematics and only $12 \%$ of the students could not answer even half of the questions. However, they did answer some of the questions and participate in the class. From another perspective, we can say that this small group of students might be the one that have really poor basic of Mathematics and a slow learner. This finding was agreed by [9] that mentioned students that entering university come from different backgrounds such as those who only know to follow formula, those who unable to solve problem without the aid of calculator and those who simply lack of self-confidence. Thus, it became a new challenge for university lecturer in assist these students.

Next, in order to measure the effectiveness of the first remedial class, this study collected the result of the students who joined the first remedial class. Then, the result was compared with the previous intake result which are the result of semester December 2015March 2016. Fig. 2 shows the comparison of passed percentage of the related semester. Passed percentage represent the percentage of students who get grade $\mathrm{C}$ to $\mathrm{A}+$.

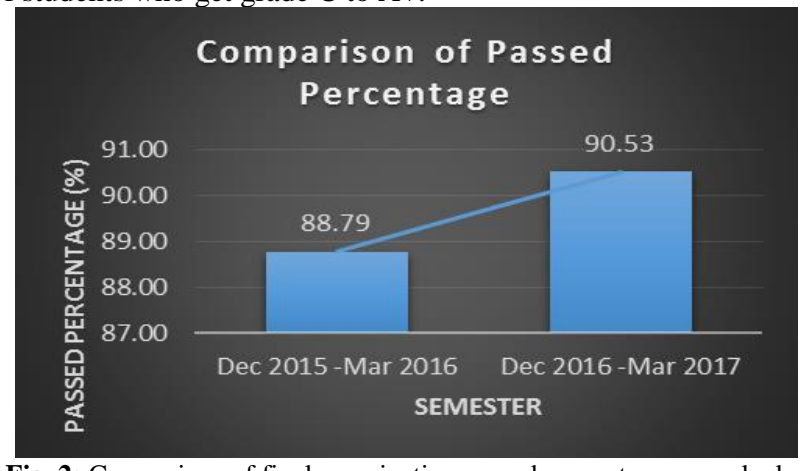

Fig. 2: Comparison of final examination passed percentage pre-calculus

The chart above shows that there is an increment in the percentage of passed between examination March 2016 and March 2017. Even though the increment is only $1.74 \%$, it still shows that there is a positive impact of the remedial class in Pre-calculus. Besides, the figure also shows that the failure rate also has decrease compare to the previous semester. Fig. 3 shows the comparison of failure rate in the two semesters.

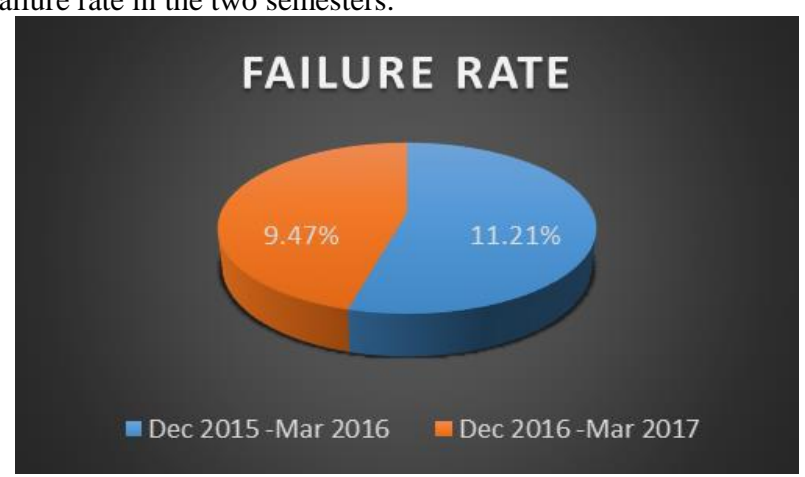

Fig. 3: Comparison of failure rate pre-calculus

Next, the result of second remedial class was measured based on the respondents' result in Calculus I. Students of Diploma in Sciences who already passed Pre-calculus need to take Calculus I in their second semester. To ensure that students do not fail this subject, second remedial class was designed and conducted in the early semester. Students were divided into two groups which are control group and experimental group. Control group involved students who attend only the first remedial class while experimental group involved those who attend both remedial classes. The result of Calculus I for both groups later was compared and used to determine the effectiveness of the second remedial class. Fig. 4 shows the comparison of passed percentage for control group and experimental group. It shows that students who attend 
the second remedial class has higher chances to pass the subject. Besides, the failure rate of students in experimental group is slightly lower than control group. The figure was shown in Fig. 5. When the failure rate is lower, students has a lower chance to fail the subject and lower possibilities to extend their study. Therefore, faculty do not have to worry about Graduates on Time of their students.

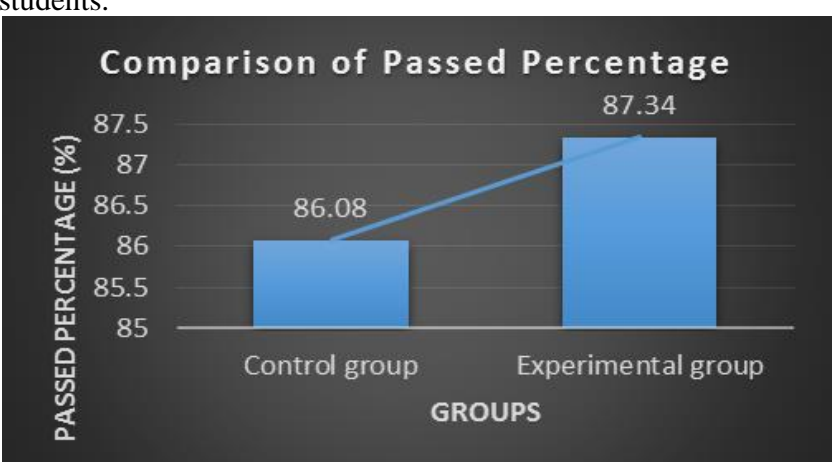

Fig. 4: Comparison of final examination passed percentage Calculus I

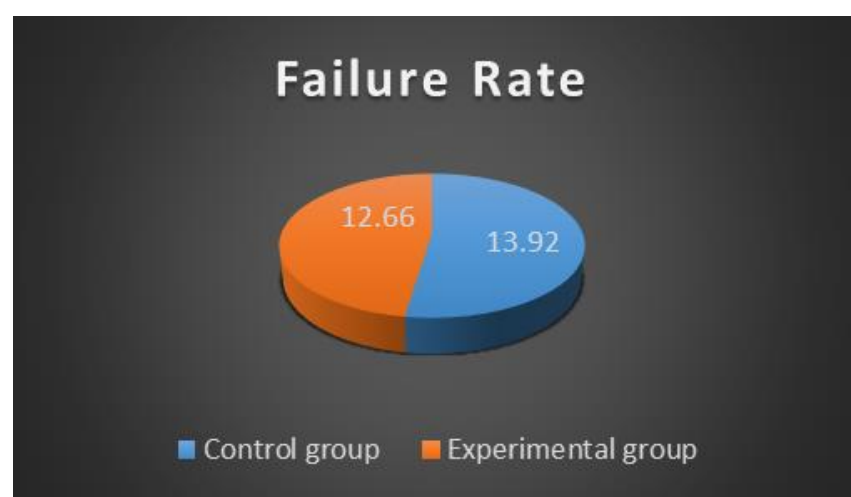

Fig. 5: Comparison of failure rate Calculus I

\section{Conclusion}

In conclusion, the multi-level remedial class introduced in this study has positive impact on the students' performance in Mathematical courses.

The first research objective was achieved when the remedial class received active learning engagement from the students. 169 students have cooperated in the study and try to improve their foundation in Mathematics for the whole two semesters. The implementation of multi-level remedial class was a good choice as students of Diploma in Sciences have pre-requisite Mathematical courses such as Pre-calculus and Calculus I. It was found that about $36 \%$ of the respondents has answered all the questions given and 52\% answered more than half and the rest answered less than half. This figure shows the support given by students in improving their basic foundation in Mathematics. Besides, the module was well-designed based on the finding in [3].

From previous studies, researchers have recommended remedial class as an approach to improve students' foundation. However, since the Mathematical courses for Diploma in Sciences are prerequisite courses, this research propose a multi-level remedial class to provide extra support for all students and reduce the number of students that do not graduate on time. First remedial class conducted to prepare students before taking Pre-calculus, while second remedial class to prepare students who are going to sit for Calculus I. By providing this remedial class in the early semester, it helps students to improve their basic foundation and prepare themselves for the semester. The multi-level remedial class shown a positive feedback as both results in Pre-calculus and Calculus I were improving. The failure rate of the students who participate in the first remedial class is much lower than the previous semester. In addition, the failure rate of students from experimental groups is slightly lower compare to control group. Thus, it shows that this multi-level remedial class has positive impact on students' performance.

For future improvement, we would like to suggest the implication of multi-level remedial class to any other programmes especially for the one that have pre-requisite Mathematical courses. It is because students will be given opportunity to receive gradual help from an experience instructor in the early semester. This remedial class definitely will benefit both the students and the faculty itself.

\section{Acknowledgement}

We would like to thanks to Universiti Teknologi MARA for the financial support under grant scheme 600-IRMI/DANA 5/3/ARAS (0170/2016).

\section{References}

[1] Akinsola MK, Tella A (2003), Effectiveness of individualistic and cooperative teaching strategies in learning geometry and problem solving in Mathematics among junior secondary schools in Nigeria. Personality Study and Group Behaviour 23, 95-105.

[2] Uche NVA, Kamoru OU (2002), Training of undergraduate teachers in Nigerian universities: Focus on problems of effective integration and attitude of students to computers in mathematics instruction. http://www.math.uocgr/ ictm2/ Proceeding/gap119pdf.

[3] Nasir AM, Omar NAB, Sarudin ESB, Masrom S, Ahmad NH (2017), Teaching and learning of pre-calculus: An insights of educators. Journal of Fundamental and Applied Sciences, 9(6S), 452 467.

[4] Ennis T, Sullivan J, Louie B, Knight D (2013), Unlocking the gate to calculus success: Pre-calculus for engineers-An assertive approach to readying underprepared students. Proceedings of the $120^{\text {th }}$ ASEE Annual Conference and Exposition, American Society for Engineering Education, pp. 1-23.

[5] Tang HE, Voon LL \& Julaihi NH (2008), The impact of 'highfailure rate' Mathematics courses on UiTM Sarawak full-time diploma students' academic performance. Universiti Teknologi MA$R A$.

[6] Gynnild V, Tyssedal J\& Lorentzen L (2005), Approaches to study and the quality of learning. Some empirical evidence from engineering education. International Journal of Science and Mathemat ics Education 3(4), 587-607.

[7] Yusof Y M \& Rahman RA (2001), Mathematics education at Universiti Teknologi Malaysia (UTM): Learning from experience. Jurnal Teknologi, 34, 9-24.

[8] Yudariah M Y \& Roselainy A R (1997), An assessment of the modular approach in teaching and learning first year calculus at UTM. Proceedings of the Conference on Science and Technology Education, pp. 15-16.

[9] Khouyibaba, S (2015). Teaching remedial courses: Challenges and teaching philosophy. Procedia-Social and Behavioral Sciences 186 927-931.

[10] Kasran, S. B., Toran, H., \& Amin, A. M (2012), Issues and trends in remedial education: What do the teachers say? Procedia-Social and Behavioral Sciences 47, 1597-1604.

[11] Diaz, P., \& Rodriquez, L. J (2013), Experiences in Spanish Universities to reduce failure in Mathematics of incoming students. Procedia-Social and Behavioral Sciences 93, 2006-2009. 